Gold Ducat of James $V$ of Scotland. This coin, the bonnet piece, shows James wearing the insignia of the Order of the Thistle. Its life-like quality gives an indication of his character, which enabled him to survive all the attacks of his own nobles as well as his neighbour, Henry VIII.

Silver Petition Crown of Charles II. Thomas Simon had been chief engraver to Cromwell. At the Restoration he was displaced by Roettier, a Dutch artist, who had worked for Charles during his exile. Roettier engraved a fine new crown piece but Simon, using the same design as a model, improved upon it by superior engraving and delicacy of touch. Round the rim in minute lettering is the Petition: 'Thomas Simon most humbly prays Your Majesty to compare this his tryall piece with the Dutch and if it were truly drawn and embossed, more gracefully order'd and more accurately engraven to relieve him.' Alas, Simon's plea was unsuccessful and he retired on a small pension and is believed to have died in 1665 during the Great Plague.

\title{
THE SEVENTIETH ORDINARY MEETING
}

This meeting was held at the University of Stirling on 17 June 1972. Professor D. A. G. Waddell, Head of the Department of History at the University, arranged an attractive programme, three members of his staff reading papers. Following the meeting Professor Waddell took the members and their guests on a conducted tour of the handsome new buildings of this delightfully sited university.

The first of the three papers was given by Dr. Anand C. Chitnis, Lecturer, who spoke on:

\section{MEDICAL EDUCATION IN EDINBURGH, 1790-1826, AND SOME VICTORIAN SOCIAL CONSEQUENCES}

It has long been recognized that medical education in Edinburgh was outstanding from the mid-eighteenth to the early nineteenth centuries. In terms of numbers, the Faculty of Medicine, certainly between 1811 and 1825, taught approximately half of the matriculated students at the university. In terms of the education available, the Faculty and the Royal Colleges of Physicians and of Surgeons claimed highly reputable teachers who introduced new, and expanded existing, didactic techniques based on observation, experimentation and practice. By 1790, the Edinburgh medical school already had an international reputation and Edinburgh was the first city in Britain which afforded concurrently a university medical school, Royal Colleges, many private lecturers and extensive hospital and dispensary facilities.

Developments in medical education were not isolated, however, during this period. It was the era of the Scottish Enlightenment, for example, the writings of David Hume and Adam Smith; the work of such men of diverse accomplishments as Watt, Raeburn and Adam; the building of the Edinburgh New Town; the foundation of the Royal Society of Edinburgh, the Encyclopaedia Britannica, and the Edinburgh Review. Medicine played an equally crucial part in the history of the Scottish Enlightenment alongside these and other men and measures. 


\section{The Scottish Society of the History of Medicine}

This paper discusses the Edinburgh medical school between 1790 and 1826, considers the medical teachers of the period, their methods of training and coursesfactors that would have been brought to bear on their students-and gives an account of Edinburgh-trained men who subsequently played important parts in several fields of medical endeavour.

While neither Edinburgh's university nor her Royal Colleges monopolised the education of the most distinguished nineteenth-century British medical practitioners, they did produce the majority of systematically trained doctors, and an estimated one-third of those serving in the medical departments of the Army, Navy and East India Company. There is much evidence as to the quality of medical education available in Edinburgh and the calibre of doctor it was designed to train. In their Report, the Commissioners (1826) concluded: 'The Medical Department of Education in the Universities of Scotland is evidently of the greatest importance. During a long period, a very large proportion of the persons who have practised Medicine throughout the country, and who have occupied the medical stations in the army and navy, have been educated for their profession in one or other of those universities. The Medical School of Edinburgh has, indeed, long possessed very high celebrity.'

The relationship between the different branches of the Edinburgh medical schoolthe University and Royal Colleges-was such that those studying for a college diploma could attend university lectures and university students attended the extra-mural lectures particularly in anatomy. In 1806, the College of Surgeons revised its examination requirements for the award of diplomas and certificates. In 1824, the university revised its statutes for the degree of M.D. Prior to 1824, the M.D. course lasted three years and classes were to be attended (some not compulsorily) in anatomy, surgery, materia medica, pharmacy, the theory and practice of medicine, clinical medicine, midwifery, chemistry and botany. Three months' courses were also required in two of the following - practical anatomy, natural history, medical jurisprudence, clinical surgery and military surgery. By the time of the 1826 Commission, there were few differences between the curricula of the University and College of Surgeons. The distinction lay more in an education given by professed teachers at the university and lectures given almost as a sideline by professional surgeons. The university provided teachers, courses and facilities-a systematic means of fulfilling the university's requirements. The college was not as well equipped with facilities or a full range of teachers.

Let us now turn and look at the professors and teachers, their courses and methods of instruction which medical students of the period under review would have met at Edinburgh.

The teachers of anatomy included Alexander Monro secundus and tertius within the university and John Barclay, John Gordon, John Bell and Robert Knox without. There was a large demand for anatomical instruction because so many students were coming for medical education and because anatomy was a basic requirement for the college's diploma, the university M.D. and for public boards and service. The second Monro was the discoverer of the opening in the cerebral ventricles known as the Foramen of Monro. His class attendance, in the only years for which figures are available, ranged from 307 in 1794 (out of a total of 374 medical students) to 333 out of 387 


\section{The Scottish Society of the History of Medicine}

medical students in 1797-98. He was succeeded by his son who had to compete with the high calibre of extra-mural teachers of anatomy and who had great difficulty in producing cadavers. His class attendances dropped from 306 out of 417 medical students in 1799 to 205 out of 817 in 1821 . He instructed by lecture-demonstration rather than allowing students to undertake individual dissection and he illustrated the structure and position of all parts of the human body and that of several inferior animals. He explained the uses of bodily organs, the diseases to which they were liable, symptoms and methods of treatment. The extra-mural anatomists to whom the students were going at the time of the third Monro included the stimulating John Barclay. He demonstrated careful observation; furthered scientific research not only by framing a new anatomical nomenclature but also by emphasizing comparative anatomy. In this way he anticipated future scientific and medical approach by his work on nonhuman species.

The two anatomical museums belonged to the University and the College of Surgeons. The college had begun its collection in 1804 but it grew slowly prior to 1823 and it was only in that year that a museum could be said to have been founded. Robert Knox became its curator then and the collection of Charles Bell, formerly housed in the Windmill Street Anatomical School, London, was purchased. Knox's plan was to form a Museum of Comparative Anatomy in which there were to be two divisions: the first was one of anatomical sciences which showed the structure and organization of animal bodies; the second was one of anatomical art which showed manual or power-driven contrivances for demonstrating organisms. Together with Barclay's bequest of his own collection, in 1826, the museum became second only to the Hunterian. The Surgeons' Museum was used by James Russell and George Ballingall for their respective clinical surgery and military surgery classes, and the plan at the time of the Commission was for alumni of the College, all over the world, to send specimens. The University's Museum was one of anatomical preparations largely bequeathed by the second Monro and to which additions had been made. Its purpose was to demonstrate and explain to students the structure, physiology and diseases of the human body.

The two professors of materia medica of the period were James Home and Andrew Duncan junior. Their courses covered pharmacology, dietetics, pharmacy, the art of prescription writing, and the connection of these matters with physiology, natural history, therapeutics and the practice of physic. The professor of materia medica was required to be a practising physician. Home and Duncan were two professors who illustrate how in the late eighteenth and early nineteenth centuries Edinburgh's method of teaching increasingly came to emphasize observation and experiment. Duncan's method of teaching included lectures, experiments, exhibitions of specimens and plates, and the introduction of pharmaceutical trials. He also had a considerable collection of pharmaceutical apparatus and a valuable and extensive collection of materia medica which he housed in a museum. He reported to the 1826 Commission that he exhibited in his classes, 'the most complete collection that, I believe, is exhibited by any lecturer in the Kingdom.' The exhibition was designed to excite the students' interest and to impart information. The specimens were 'so laid out that there is no interruption [of the lecture] and, in general, a considerable time is employed after each lecture by the 


\section{The Scottish Society of the History of Medicine}

students coming down to the table, which is very large, and examining the specimens, and in tasting and smelling them, and otherwise acquiring a knowledge of them.'

James Gregory, professor of medicine from 1790-1821, is one of the celebrities of Edinburgh medical history, renowned for the number of doctors he trained. The Quarterly Journal of Education reported that 'As a lecturer he was without rival-dignified, eloquent, and forcible. Never perhaps again will the medical student possess the rare advantage of following so clear, so powerful, and so sincere a mind through all the labyrinths, and mysteries, and mummeries of medicine.' The Journal went on to compare his relationship to his students as similar to the ancient Greek philosophers.

Gregory was succeeded by James Home who introduced examinations into his method of teaching. He told the Commission of the advantages of supplementing lectures by examinations: 'it forces my students to attend more carefully and pointedly to the lectures; it obliges them, from the strictness of the examination, to read at home, and to make the information they get from me, or from books, much more their own. It brings me much more in immediate contact with the young gentlemen, and I am enabled to know a great deal of their talents, character, and information, before they come for private examination for a Degree.'

Home emphasized medical practice as opposed to theory, in the examination: 'I ask the symptoms of disease-the mode of distinguishing one disease from others nearly connected with it; and when I come to the treatment, I ask them in a very particular manner as to that. I should hope they get that information from their attention to minutiae which it would be impossible in any lecture to give. . . . I confine myself to mere fact. The consequence is that those gentlemen are certainly the best informed, with regard to these minutiae, that come before us.'

What emerges from Home's evidence is a clear desire to know the students whom he was teaching and to send them out as knowledgeable medical practitioners. He shared with his professorial colleagues a faith in education and sought to implement that faith by giving an importance to examinations. Gregory's influence to the same end was achieved by personal example.

The chair of midwifery was monopolized by Alexander and James Hamilton, father and son, from 1780 to 1840 . Despite midwifery not being a compulsory subject, Alexander's class attendances ranged from 79 in 1794 to 168 in 1799, and James continued the trend reaching 240 in 1802, 250 in 1807, and 315 in 1816. Both men divided their course into four parts. Alexander covered the prenatal conditions of women, the treatment of all the various conditions which could occur, the management of expectant women and the treatment of infant disorders. James dealt with the anatomy and physiology of the reproductive system, including questions concerning the foetus, the changes consequent upon childbirth, and medico-legal matters concerning the infant's viability and proofs of child-murder. His second, third and fourth parts were similar to those of his father.

In 1791 Alexander Hamilton requested the University Senate to provide a General Lying-in Hospital. Prior to this provision, his students had practised midwifery in the lying-in ward of the Royal Infirmary but it was too small, providing for only six patients at a time. Those pupils anxious to increase their knowledge and experience were allowed to accompany him to private deliveries. In 1792 a lying-in hospital was 


\section{The Scottish Society of the History of Medicine}

established independently to help needy women and to give students practical opportunities to study midwifery and the newborn infant. James extended the service to women in their own homes, "to afford every requisite attendance, either by a Medical Gentleman, or a Midwife (as circumstances may require), to Poor Married women lying-in at their own habitation; to furnish them with the necessary Medicines; to supply the most needy of them with the temporary use of Child-bed Linen, Flannels, Blankets, etc., and with any other addition to the means of comfort and health that may be essentially necessary. At present there is not any Public Institution of the same kind established in this City, embracing such manifold advantages to the Industrious Poor at such a period of anxiety, when all the evils of Poverty are felt in an accumulated degree.' James also had a museum of his own which cost him $£ 1,200$ and he also gave private instruction to midwives.

Clinical medicine and surgery were introduced into Britain at Edinburgh and by 1826 it was still almost confined to the Scottish capital. Special wards were set aside at the Royal Infirmary for this instruction. Andrew Duncan junior left valuable and detailed accounts of the conduct of the clinical medicine course in his evidence to the 1826 Commission and in his book, Reports of the Practice in the Clinical Wards of the Royal Infirmary of Edinburgh (1818). While he recognized that the primary function of hospitals was the restoration of health to the sick he also saw them as necessarily giving practitioners personal experience and the pupils much valuable instruction. The clinical medicine course therefore was not only directed towards curing patients but was an invaluable teaching instrument and provided a fund of medical knowledge.

James Gregory had a great reputation as a clinical teacher. Sir Astley Cooper in evidence before the 1834 Committee on Medical Education commented: 'I do not think I acquired such substantial knowledge of practical medicine anywhere as from Dr. Gregory's clinical lectures.'

The first incumbent of the chair of clinical surgery was James Russell who held the post from 1803 to 1833 . He believed that a chair in clinical surgery would complete the medical education available in Edinburgh although bedside surgical teaching had been given at the Royal Infirmary since 1729 and clinical surgical lectures since 1766.

In 1806 the scope of the medical school's teaching was further widened to include military surgery by the endowment by government of a chair of military surgery. The class seems to have originated from the contact which John Thomson, the chair's first incumbent until 1823, and Sir George Ballingall, his successor until 1856, had had with the French wars and was an obvious and sensible response to the need for medical officers in the armed forces. The University of Edinburgh was the only institution in Britain which could absorb an extra course of this nature into a systematic medical curriculum, and this explains why so many of the members of the medical departments of the army and navy were former Edinburgh students. In 1806, Lord Moira, who had been Commander-in-Chief in Scotland in 1803 and on whose staff Thomson had served, became Master-General of the Ordnance in the 'Ministry of All the Talents', thus giving Thomson access to government patronage.

Thomson and Ballingall were enthusiastic teachers and experienced in their profession. Thomson had given an extra-mural class in military surgery in 1804; in 1814 he toured medical schools in France, Italy, Austria, Saxony, Prussia, Hanover and 


\section{The Scottish Society of the History of Medicine}

Holland; and in 1815 he was a staff-surgeon in Belgium and was at Waterloo. Ballingall was in the army from 1806 to 1808 , serving in India, Java and France. He wrote a book on the construction of hospitals. The class appears to have been a success. Thomson failed to keep a class register but a student wrote that in 1815-16 between 250-280 students crowded into his classroom. The students were lively and interested: 'The army and navy surgeons especially used almost invariably to carry on a keen discussion on the merits of the doctrines propounded in the lecture.' Of the chair, Sir James McGrigor commented that it had been a valuable addition to the medical faculty.

The chair of medical jurisprudence was founded in 1807 in response to Andrew Duncan senior's petition that there was much emphasis placed on the subject on the Continent; that it would facilitate important improvements in the regulation of hospitals for the diseased, aged, indigent and insane; and that it would show that Edinburgh did not neglect any branch of medicine. Prior to 1807, Duncan senior had, since 1795, lectured on forensic medicine and 'medical police'-incorporating both personal and environmental health.

Andrew Duncan senior also proposed, in 1792, the erection of a public Lunatic Asylum. This was nine years before the appearance of Philippe Pinel's Traité medicophilosophique sur l'Alienation mentale, although Duncan's hospital was not erected until 1807. Duncan was motivated by the death of the young Scottish poet, Robert Ferguson, who, suffering from severe mental illness, could only be moved from his home to the city's bedlam where he died. Later, W. P. Alison who supported Alexander Morison's plan for a university chair of mental diseases, included the subject in his institutes of medicine course. As Alison told the Royal Commission, 'A number of men study here, who afterwards become physicians to Lunatic Hospitals in different parts of the country, and have the charge of many persons there confined, and to whom it is an object to have the cure of such patients.' The Commission decided that 'it does not appear that this class of diseases can be examined as their vast importance requires, when merely incidentally treated in an ordinary Course on the Practice of Medicine; and if that be the case, there can be little hesitation, both with a view to the interests of humanity and of science, that a Chair of the nature mentioned should be attached to the University of Edinburgh.' But government, which had specifically asked the Commission to investigate the possibility, informed the Commissioners that the proposed endowment of a chair of mental diseases could not be made available.

Andrew Duncan senior's versatility showed itself too in the matter of dispensaries. His Old Town Dispensary, founded in 1776, was developed primarily as a medical teaching centre providing different opportunities from the Infirmary. Both the Old and the New Town Dispensaries took it upon themselves to spread the practice of free inoculation, especially among the children of the poor. In 1801 Edinburgh established a vaccine institution. Between 1804 and 1806 smallpox was reckoned a rare occurrence even among the poor and the result was the establishment in London, under government direction, of the National Vaccine Institution.

In 1815 the New Town Dispensary was founded by, inter alia, John Thomson and W. P. Alison. Its objects were to afford relief to the sick and distressed poor, to provide domiciliary atttendance to pregnant women and to give free vaccination against 


\section{The Scottish Society of the History of Medicine}

smallpox to children. The founders saw the value of their institution in the fact that hospitals were expensive and overcrowded. They set out to provide for five groups of people: those with slight complaints which might grow dangerous if neglected; those among the labouring classes who needed remedies while continuing to work; those needing hospital treatment but who could not be separated from their families-especially mothers with young children; the children of the poor; and the aged poor. The Old Town Dispensary was open only twice weekly and it was not sufficient for the city's needs and its doctors made no domiciliary visits. Alison's work in the New Town Dispensary helped him in the writing of his Observations on the Management of the Poor in Scotland and its Effects on the Health of the Great Towns (1840), which formed such a major source of Scottish material for Chadwick's Sanitary Report. The medical students worked with their teachers in the dispensaries, hospitals and homes of the poor and thus received an excellent introduction to the responsibilities of a public health doctor.

Turning now to the students of the period between 1790 and 1826, there were 2,309 medical graduates of the university and 2,722 diplomas awarded by the Royal College of Surgeons. Many thousands of others studied at Edinburgh but did not graduate and many of the graduates can also be included among those taking the Surgeons' diploma. Most of the students came from Scotland but more of the graduates came from England and Ireland. Other countries represented in the student body included North America, West Indies, Portugal, Brazil, France, Italy, Germany and Switzerland. The Scottish medical student might have preceded his course with the arts' classes of the university or with up to seven years' apprenticeship. The London or Dublin student might already be a skilled anatomist or have served as a surgeon in the army or navy and have left on half-pay to complete his medical studies. There was an increase in the number of surgeons' diplomas awarded after 1811, and in the number of graduates after 1815 which can be attributed to the gradual return of men on half-pay from the French wars to complete their medical studies.

The analysis which follows of the subsequent careers of Edinburgh medical students who would have been exposed to the teaching outlined above, is based on a sample of eighty-six, whose careers are traceable from works of reference, biographies, social histories and other sources. As would be expected from the nature of the education offered, the social consequences were to be felt in four main areas of Victorian lifemedical education, mental health, public health, and medical science. It must be remembered that these areas were to be of some importance in the first industrial urban society.

Six men served conspicuously in the medical departments of the army and navy. Sir William Burnett was the navy's first Director-General of Medical Services, and was responsible for the improvement in the navy's medical condition, including the opening of the hospital at Chatham. John Liddell (M.D. and L.R.C.S. 1821) succeeded Burnett as Director-General. John Davy, brother of Sir Humphry, graduated in 1814 and rose to become Inspector-General of Hospitals. Sir James McGrigor, who had studied at Edinburgh but graduated from Aberdeen, became Director-General of the Army Medical Department and was succeeded by Sir Andrew Smith (M.D. 1819), while Thomas Shortt (M.D. 1815) was the medical officer at St. Helena during Napoleon's 


\section{The Scottish Society of the History of Medicine}

confinement there and was one of the five army doctors present at the former emperor's autopsy.

Five men became connected with the Royal Family. James Begbie was a Royal Physician in Scotland, Sir William Knighton was physician to George IV and Keeper of the Privy Purse, and Sir Henry Holland was physician to Queen Victoria. James Wardrop was George IV's oculist and Sir Charles Locock attended Queen Victoria at the births of all her children. Five of the seven nominees for Fellowships of the Royal College of Physicians of London during the presidency of Sir Henry Holford were former Edinburgh students-Sir Henry Holland, Henry Herbert Southey, Sir James McGrigor, Peter Mark Roget, and William Prout.

Edinburgh alumni also made important contributions to medical science. Richard Bright was to show that dropsy could be the result of kidney disease; Thomas Addison undertook original research into appendicitis and gave his name to two disorders; Marshall Hall discovered human reflex action; on Christmas Day 1809, Ephraim McDowell of Kentucky performed the first successful operation to remove an ovarian tumour; and Philip Syng Physick was the first North American to wash out the stomach with a tube in a case of poisoning.

Two fields of endeavour in which former Edinburgh students figured prominently were mental health and public health and are of importance in assessing the contribution of the medical school's training for nineteenth-century social problems. In mental health, legislation was passed in 1828 to provide for fifteen Metropolitan Commissioners in Lunacy and in $\mathbf{1 8 4 5}$ to provide Commissioners for the entire country. Four of the fifteen first appointed Metropolitan Commissioners were former Edinburgh students. They were Thomas Drever (M.D. 1798), H. H. Southey (M.D. 1806). Thomas Turner (who studied at Edinburgh during the 1820s), and John Robert Hume (M.D. 1803). Later appointees included William Alexander Francis Browne (L.R.C.S. 1826) who was the first Commissioner in Lunacy in Scotland; Cornwallis Hewett, who studied at Edinburgh c. 1809, became a medical professor at Cambridge, and was a Commissioner from 1840-41 ; John Cowles Prichard (M.D. 1808) a noted anthropologist and the first practising psychiatrist to serve as a Commissioner (1845-48); and Edward James Seymour who studied at Edinburgh from 1816-18 and was a Commissioner from 1831-39. Browne, Prichard and Seymour were also distinguished mental health specialists and among other Edinburgh-trained men who were also active professionally - as opposed to serving as government officers-were John Conolly (M.D. 1821), James Douglas (M.R.C.S. 1820), Thomas Hancock (M.D. 1806), Sir Alexander Morison (M.D. 1799), Henry Reeve (M.D. 1803), John Reid (M.D. 1798), and William Thomson (M.D. 1824 or 1827).

Browne was medical superintendent of the Royal Asylum, Montrose, from 1834, and of the Crichton Institution, Dumfries, from 1839. His What Asylums were, are, and ought to be (1837) was a manifesto for ameliorating the treatment of the mentally sick, and he also foresaw the advantages of group therapy. Prichard was the first British psychiatrist to distinguish moral insanity from other forms such as delusions and hallucinations. Hancock was responsible for publicizing the need in London for an asylum similar to the Retreat in York. Reid saw that asylum treatment could often instil rather than cure madness. Seymour similarly stressed the need for improved 


\section{The Scottish Society of the History of Medicine}

outpatient facilities rather than immuring the mentally afflicted in the social isolation of hospitals and away from their home environments. Reeve and Thomson both worked in asylums-Reeve in Norwich and Thomson in Glasgow.

Sir Alexander Morison and John Conolly are highly distinguished figures in the history of psychiatry, ranking with Pinel and Esquirol. Morison was a student of Andrew Duncan senior, the founder of the Royal Edinburgh Hospital for Mental Disorders. In 1810, he was inspecting physician of lunatic asylums in Surrey and in 1823 he suggested that Edinburgh University establish a chair of mental diseases, for which idea he received the backing of the wife of the banker, Thomas Coutts. This plan did not receive much support and so, in 1823, Morison began a course of nine private lectures which continued for thirty years and which comprised the first course on mental diseases to be given in Britain. He also founded the Morison Lectureship at the Royal College of Physicians of Edinburgh to promote the study of mental disorder in 1864.

The work of John Conolly in public health, but especially in that of mental disorders is too little known. His thesis, De Statu Mentis in Insania et Melancholia made the point, little appreciated at the time, that the healthy mind had to be understood in order to cure the sick one. He also emphasized his dislike of the asylum system. He first practised at Chichester which suffered a smallpox outbreak because of the low rate of vaccination especially among the poorer folk. In 1822 he wrote An Address to Parents on the present state of Vaccination in this Country. In the same year he moved to Stratford where he became twice mayor and initiated many social and sanitary improvements, including the establishment of a public dispensary, later the Stratfordupon-Avon Hospital, which offered free vaccination among its services. From 1827-31 he was professor of the nature and treatment of diseases at the new University College, London. He was pre-occupied with the problems of insanity but his offer to lecture on the subject was rejected by the College Council. He returned to practise at Warwick until 1839 and during that time was visiting physician to the Warwickshire Lunatic Asylums. It was in 1839 that his practical work in mental health began-he became resident physician at the Middlesex County Asylum at Hanwell where he remained until 1843.

Hanwell was the largest asylum in the country and Conolly introduced the nonrestraint scheme there. In his M.D. thesis he acknowledged the work of the Tukes at York when he wrote: 'I do not hesitate to assert that the more insane persons would be cured if moral treatment were better understood and administered in time . . . in Britain the credit for this kind of treatment justly belongs to the Friends.' Hanwell was much visited and even Samuel Tuke was impressed, for, in addition to sending his son to study under Conolly there, he wrote: 'From the zeal, talents, and integrity of Dr. Conolly, we shall doubtless learn in the most satisfactory manner the further results of this large and most satisfactory experiment.' At Hanwell in 1842 Conolly gave formal clinical instruction in mental diseases, the first course of its kind in England, to students from London medical schools. He expounded the theory behind non-restraint as well as its practice, advocated the attaching of clinical teaching schools to asylums and the provision by local health services of in-patient and domiciliary treatment.

The contribution to nineteenth-century public health of three Edinburgh-trained 


\section{The Scottish Society of the History of Medicine}

men, James Moncrieff Arnott, James Phillips Kay-Shuttleworth and Thomas Southwood Smith has been ably documented. Smith (1923) biographer of Kay-Shuttleworth, certainly believed that his subject's experiences in the Edinburgh New Town Dispensary and the Queensferry Fever Hospital, under the supervision of W. P. Alison, made Kay-Shuttleworth a social reformer. Other Edinburgh-trained men performed no less valuable work in the public health field although their impact was more local. Malachi Blake (M.D. 1793) was the moving spirit behind the foundation of the Taunton and Somerset Hospital; Joseph Brown (M.D. 1819) was an ardent reformer of sanitation in Sunderland where he became mayor; Francis Cooper (L.R.C.S. 1827) was Southampton's medical officer of health from 1850 and died of cholera there in 1865 while still in office; George Cuming (M.D. 1802) formed and managed the Denbighshire Infirmary and general dispensary; Sir Charles Hastings (M.D. 1818) not only founded the British Medical Association but was also president of the public health section of the Social Science Association; and William Henry (M.D. 1807) wrote an elaborate report on the 1834 cholera epidemic for the British Association. Joseph Hume (M.R.C.S. 1796), a well-known Radical, was chairman of the select committee of M.P.s to examine how far the principles of the Health of Towns Commission could be carried out with respect to waterworks and drainage; William Kay (M.D. 1827) was medical officer of health of Merthyr Tydfil from 1853-55 and the author of a sanitary report on Bristol and Clifton in 1842; Sir Richard Owen, who studied at Edinburgh from 1824, served with Edwin Chadwick on the 1847 Royal Commission on London; John Roberton (L.R.C.S. 1817) was concerned with hospital construction in Warrington and wrote a treatise on medical police; Seymour, the Lunacy Commissioner, was secretary of the Central Board of Health in 1831; John Sutherland (L.R.C.S. 1827; M.D. 1831) was an inspector under the first Board of Health in 1848, editor of the Journal of Public Health and Monthly Record of Sanitary Improvement, and founder in 1844 of the Liverpool Health of Towns' Advocate; and John Wilson (M.D. 1823) became Inspector-General of Hospitals.

The contribution of Edinburgh-trained medical men from 1790-1826 to all these spheres - the armed forces, medical science and teaching, lunacy and public healthwas considerable.

Conceding that medical education at Edinburgh was the most complete in Britain at the time under review, it was but natural that Edinburgh-trained men should be actively concerned in the development of medical education at other centres both at home and abroad. The institutions at home with which they were concerned were Cambridge, the new London University, new and existing London hospitals, Dublin, Manchester, Liverpool, Bristol, Newcastle and St. Andrews. John Haviland studied at Edinburgh between 1807-9 and became professor of anatomy at Cambridge in 1814 and regius professor of physic there in 1817. He was the first professor of both subjects to give a regular course of lectures at Cambridge- At his suggestion and by his efforts a lengthened and systematic course of study has been required, rigid examinations have been instituted, and lectures on various branches of medicine, and the collateral sciences, have been regularly given in the medical school of the University.' In 1821 the Cambridge Senate made two terms of lectures from him a requirement for the degree; in 1827 every Cambridge medical student-unless licensed by the London 


\section{The Scottish Society of the History of Medicine}

College of Physicians-had to undergo the M.B. examination and after 1827, a Syndicate was appointed to enquire into medical degrees and examinations. They recommended that the anatomy, chemistry and botany professors assist Haviland in the examination, and that the examination cover pathology, the practice of medicine, clinical medicine, anatomy, physiology, chemical pharmacy and botany's relation to medicine.

To Joseph Jordan has been ascribed the title Father of Provincial Medical Education. Educated at Edinburgh and both Royal Colleges of Edinburgh he started the school of medicine at Manchester. James Carson (M.D. 1799) became the authority in the Liverpool medical school on the circulation and respiration. William Kay, previously noted as a medical officer of health, became a lecturer on forensic medicine at the Bristol medical school. George Fife (M.D. 1827) became the first lecturer in medical jurisprudence and materia medica in the Newcastle upon Tyne medical school, and John Reid became professor of anatomy at St. Andrews.

It was to Dublin and London medical schools that Edinburgh's contribution was greatest. To Dublin returned Abraham Colles, James O'Beirne, Thomas Beatty, John Cheyne, Sir Dominic Corrigan, Robert Graves and William Stokes. Colles (M.D. 1797) became professor of anatomy, physiology and surgery at the Dublin College of Surgeons; O'Beirne (M.D. 1818) was surgeon to several Dublin hospitals while Beatty (M.D. 1820) wrote much on medicine and midwifery. Cheyne (M.D. 1795) became professor of medicine at the Dublin College of Surgeons in 1811 and was the founder of clinical teaching at Dublin. Corrigan (M.D. 1825) was physician to several Dublin hospitals and lectured on the practice of medicine. He was five times president of the Royal College of Physicians in Ireland. Graves (M.D. 1819) became professor of physiology at Dublin while Stokes (M.D. 1825) was appointed regius professor of physic at Dublin.

Eight of the first professors of medicine at University College, London, had been educated at Edinburgh. Robert Grant, professor of comparative anatomy, was a colleague of Charles Darwin. Charles Bell, renowned for his work on the nervous system, was not only a professor at the new University College but in 1835 founded the Middlesex Hospital Medical School. Anthony Todd Thomson, founder of the Chelsea, Brompton and Belgrave Dispensary, was professor of materia medica from 1826-49 and of medical jurisprudence from 1830. John Conolly, as previously noted, was professor of the nature and treatment of diseases. The first professor of medical jurisprudence was John Gordon Smith who had graduated with highest honours in medicine in 1810. John Elliostson and Robert Liston held chairs of the principles and practice of medicine and of clinical surgery respectively. William Sharpey, secretary of the Royal Society from 1853-72, was the eighth Edinburgh-trained man and became professor of anatomy and physiology.

Guy's Hospital was the other London centre to which Edinburgh alumni of 17901826 flocked. They included Richard Bright, Thomas Addison and Thomas Hodgkin who founded the Guy's Society for Clinical Reports. Others who were physicians at the hospital included Alexander Marcet, James Laird, and William Back. James Blundell (M.D. 1813) was lecturer in obstetrics. Physicians at other London hospitals included James Hope at St. George's and Thomas Bradley at Westminster. At the 


\section{The Scottish Society of the History of Medicine}

teaching level were James Moncrieff Arnott, a co-founder with Charles Bell of the Middlesex Hospital Medical School; Thomas Watson, professor of forensic medicine at the Middlesex and King's; and Robert Ferguson, professor of midwifery at King's.

It is clear that whether one considers Edinburgh's anatomical museums, lying-in hospitals, the Royal Infirmary or dispensaries from 1790-1826, the purpose of medical education lies behind them all. The particular medical professors and teachers introduced new techniques and facilities or expanded existing ones in order to extend knowledge of medical science and produce better doctors. They were supported in their endeavours by the professors of the pre-medical subjects-especially botany and natural history-who emphasized careful and systematic observation in their training. The dual functions of the Royal Infirmary were clear. Daniel Ellis wrote in 1814 that: The senior surgeons executed the duties of attendance on the sick, and performed capital operations; while to the juniors was assigned the duty of acting in the absence of the seniors, of assisting them in their operations, of visiting the patients who require surgical aid in the medical wards and of preparing for exhibition such cases of morbid dissection as occurred in the hospital and might be deemed interesting for the illustration of disease.'

The Edinburgh medical school was the only one of its kind in the country but the professors were not content to rest on the foundations laid in the late eighteenth century. Men of Gregory's and Alison's calibre were examples to aspiring doctors. New chairs of clinical and military surgery and medical jursiprudence were founded. The extra-mural anatomists introduced new analysis and comparative anatomy. The importance of mental disorder and of public health was realized. In all these ways Edinburgh showed a high degree of specialization, a concern for knowledge and an appreciation of the importance of education.

The results were constructive; students emerged who had captured the enthusiasm of their teachers. Some became teachers themselves and either modelled the schools they founded on their Alma Mater, introduced the Edinburgh concept of attaching a a medical school to a hospital or inaugurated clinical lectures in specialized fields. Still more benefited from the establishment of the military surgery course and were equipped to cope with the immediate health problems in the battlefields of the Napoleonic wars. In the longer term, preparation had been given for the needs of the nineteenth-century industrial and urban society that is associated with the reign of Queen Victoria. In public health, mental health, medical science, and medical education former Edinburgh students excelled just as their Alma Mater had emphasized precisely those areas of activity. Furthermore, there is reason to believe that the measures instituted by Edinburgh-trained medical men contributed to the remarkable stability of Victorian society and which made it one of the glorious periods of our history.

\section{REFERENCES}

Evidence, oral and documentary, taken and received by the Commissioners appointed in 1826, and re-appointed in 1830, for visiting the Universities of Scotland, University of Edinburgh, 4 vols., Vol. 1, 1837.

Report of Royal Commission of Inquiry into the state of the Universities of Scotland, 1831. Report of Select Committee on Medical Education, 1834.

BOWER, A., History of the University of Edinburgh, 3 vols., Edinburgh, 1830. 


\section{The Scottish Society of the History of Medicine}

Bristed, J., A Pedestrian Tour through Part of the Highlands of Scotland in 1801, 2 vols., London, 1803.

Brockbank, E. M., The Foundation of Provincial Medical Education in England, and of the Manchester School in particular, Manchester, 1936.

CuIrNIs, A. C., 'The Edinburgh professoriate and the University's contribution to nineteenth century British society', Ph.D. thesis, University of Edinburgh, 1968.

Clark, G. N., A History of the Royal College of Physicians of London, Vol. 2, London, 1966.

COMRIE, J. D., History of Scottish Medicine, 2nd ed., 2 vols., London, 1932.

Cresswell, C. H., The Royal College of Surgeons of Edinburgh, 1505-1905, Edinburgh, 1926.

DunCAN, ANDREw, jr., Reports of the Practice in the Clinical Wards of the Royal Infirmary of Edinburgh, Edinburgh, 1818.

DunCAN, ANDREW, jr., Medical Education, Edinburgh, 1827.

Edinburgh Medical and Surgical Journal, Notice of some of the leading events in the life of the late Dr. John Thomson, 1847, 67, 164.

Report of the Royal Public Dispensary for the City and County of Edinburgh, Edinburgh, 1822.

Statement regarding the New Town Dispensary, Edinburgh, by the medical gentlemen conducting that institution, Edinburgh, 1816.

Euus, D., Memoir of the Life and Writings of John Gordon, Edinburgh, 1823.

Grant, A., Story of the University of Edinburgh, 2 vols., London, 1884.

GreenwoOd, M., Some British Pioneers of Social Medcine, London, 1948.

HAMII ton, JAMEs, Edinburgh Lying-in Institution for delivering Poor Married Women at their own Homes, Edinburgh, 1824.

Hall, C., Memoirs of Marshall Hall, London, 1861.

Holloway, S. W. F., 'Medical education in England, 1830-1858: a sociological analysis', History, 1964, 44, 299.

Hunter, R., and Macalpine, I., 'An anonymous publication on vaccination by John Conolly (1794-1866)', J. Hist. Med., 1959, 14, 312.

Hunter, R. and MaCalpine, I., Three Hundred Years of Psychiatry, 1535-1860, London, 1963.

Newman, C., The Evolution of Medical Education in the Nineteenth Century, London, 1957. Quarterly Journal of Education, 'The recent improvement of medical education', 1832, 4, 3. University of Edinburgh, Minutes of Senatus, MSS. 2, 145.

WmDEss, J. D. H., The Royal College of Surgeons in Ireland and its Medical School, 17841966, 2nd ed., Edinburgh, 1967.

Mrs. Monica Clough, also a Lecturer in the Department of History at Stirling University followed Dr. Chitnis, contributing:

\section{A RESEARCH NOTE-MATERIAL OF MEDICAL INTEREST IN THE CROMARTIE PAPERS}

The following note contains some lay reflections on the mass of medical material which may be found in collections of old family papers in Scotland. The Cromartie family papers, to which I have recently been given access, contain quite a lot of this sort of material. These papers were sorted into categories by William Fraser when he was working on the two-volume History of the Earls of Cromartie, published in 1876. He only published a fraction of the correspondence but left it all in remarkably good order. Only one category concerns us today, the rather random bundle bound together as Poetry, Medical Prescriptions and Cookery Recipes. The poetry I can judge-it is at best 'minor' and 'occasional' verse; the cookery section has not yet been looked at. 